\title{
Collaborative marketing in a premium wine region: the role of horizontal networks
}

\section{Introduction}

On a global scale, the wine industry comprises thousands of distinct geographic regions that are often marketed according to the unique strengths of their terroir. Yet, as the number of regions and wine producers continues to grow, using differentiation as a source of competitive advantage becomes more difficult. Indeed, it has been suggested that to survive in this adverse environment, wine producers should develop strong linkages with other businesses in their region, cluster and/or network (Mitchell and Schreiber, 2007; Mueller \& Sumner, 2006). These relationships can assist the region (and winery) to build strong brand identity and brand awareness, which are crucial for securing long-term success in the wine market (Bruwer, 2003). Previous studies have also found that networks and alliances between wineries are beneficial from a wine tourism perspective, however some areas warrant more attention. Randall and Mitchell (2008), for example, studied the importance relative to performance of potential outcomes associated with the Wine Islands Project, a network of small wineries and related tourism businesses located on British Columbia's Vancouver and Gulf Islands. The authors found that the network delivered benefits in terms of media coverage, brand building and increasing knowledge of the region. Thus, it appears from a wine marketing perspective small wine producers have much to gain from collaboration and networking, as by working together wine firms can significantly increase the market presence of their regional and individual brand.

From modest beginnings 200 years ago, Australia's wine industry is now positioned at the forefront of a changing international landscape (Aylward, 2006). As a key player in the New World of wine, Australia is renowned for its consistently good wines, and for innovation, strong market orientation, and diversity of climatic conditions (Jordan et al., 2007). The structure of the industry has evolved to be very fragmented, with more than 60 wine regions and around 90 per cent of producers categorised as small to medium sized enterprises (SMEs) according to their average annual grape yield. Issues such as building a brand image, establishing an identity, and maintaining infrastructure are all important at the regional level (Carlsen et al., 1998). 
The ongoing pressure associated with being a small business in a global wine market has forced many producers to adopt a more market-driven focus and to recognise that relationships with consumers, trade, and government are central to the long-term success of their business and wine region. In 2008, the outgoing General Manager of the Australian Wine and Brandy Corporation argued that producers would need to adopt a more collaborative approach to their marketing (Henry, 2008). For small producers in particular, networking and building strong relationships within their industry and supply chain can help them to sustain viability and exploit the opportunities presented by the new environment.

Previous wine business research has found that sharing technical knowledge and information is particularly valuable to small wine businesses, and that this type of collaboration has contributed vastly to the Australian wine industry's success (Marsh and Shaw, 1999). Whilst business networks represent one of the most widely studied forms of inter-organisational relationships, ambiguity still surrounds why firms join horizontal networks and how the individual firms involved perceive and manage these relationships. Furthermore, few studies have investigated the marketing and network practices of SME wineries located outside of Australia's major wine regions and states.

This paper investigates why SME wine producers join horizontal networks, and how such networks can benefit the marketing activities of individual producers and the collective. The study examines one of Australia's smallest and more premium wine regions: Tasmania. Tasmania provides an ideal context due to there being inter-organisational networks already present, and a strong collective desire for the industry to further develop its reputation for premium cool-climate wine. To begin with, this paper presents a review of the theory surrounding business networks and inter-organisational relationships. A description of the Tasmanian wine industry is then provided, followed by an overview of the research methodology, and a discussion of the study's findings and managerial implications.

\section{Theoretical framework}

\section{Defining the network construct}

A fundamental shift in business strategy has occurred in the past few decades with the emergence of the network perspective, which has coincided with increased regard for 
inter-organisational collaboration (Möller and Rajala, 2007). Current research tends to build on earlier studies in the relationship marketing and strategic alliance fields. However, the theoretical approaches used to study inter-organisational networks still appear to be varied and relatively incoherent (Cova et al., 2010). This has created confusion about what exactly the term 'network' means. For the purposes of this research, a network is defined as a set of connected firms, in which actors work together for mutual benefit over the long-term by jointly undertaking activities and sharing resources, whilst maintaining their separate entities (Anderson et al., 1994). This definition is supported in the work of Cafaggi and Iamiceli (2010), who studied the role of inter-firm collaboration and found there were two types of networks present in the European wine industry: those that were contractual and those that were merely organisational. Compared with other forms of inter-firm collaboration, networks are multilateral and contain a higher level of interdependence between the businesses involved (Cafaggi \& Iamiceli, 2010). The strength of network ties can be characterised according to the amount of time actors spend together, and the degree of mutual confiding and reciprocal services (Granovetter, 1973). Networks are also often classified according to the direction of their actor linkages (i.e., vertical or horizontal), and/or the types of firms involved (Fyall and Garrod, 2005).

Researchers applying traditional network theory have largely focused on the vertical and dyadic relationships between members of a supply chain, such as suppliers, manufacturing firms, distributors and retailers (Håkansson, 1982). Given the industrial marketing origins of the network approach, the extent of academic research on vertical networks is also more substantial. However, several authors (for example, Easton and Araujo, 1992) have highlighted the need for more research examining the nature of relationships between homogeneous firms that are located at the same point in the supply chain, namely, competitors.

\section{Horizontal networks}

Previous estimates suggest that more than 50 per cent of cooperative relationships involve competitors (Harbison and Pekar, 1998). Such arrangements benefit actors through economies of scale, and the ability to achieve superior performance when their resources and capabilities are combined (Gnyawali and Madhavan, 2001). Although some argue that collaboration between competitors may inhibit healthy competition and facilitate collusion (Porter and Fuller, 1986), others suggest that inter-competitor cooperation is one of the 
most advantageous forms of all inter-organisational relationships (Bengtsson and Kock, 2000). In the agribusiness sector, a number of producers are adopting a more collaborative approach to their marketing and management in response to vast industry change (Lindgreen, 2001). For many, their ability to survive and prosper will be tied to their ability to cooperate, rather than compete (Morris et al., 2007).

\section{Networks and relationships among wine businesses}

Although some researchers have studied collaboration and inter-organisational relationships from a wine business perspective (Brown and Butler, 1995; Lindgreen, 2001; Randall and Mitchell, 2008; Somogyi, 2013; Taplin, 2010; Telfer, 2001; Thach and Olson, 2006), few have specifically examined relationships and networks between the producers themselves. Collectively, SME wine producers can make improvements to the production quality of their wine product, and increase their market reach and presence (ACIL Consultants, 2003). Collaboration at an industry level can also enable producers to use and spread information more productively (Anderson, 2001), which supports their ability to gain knowledge, and understanding of markets and consumer needs. Networks have also been important in the development of wine tourism. In Australia and New Zealand many networks have been established to facilitate and coordinate the development of wine routes and attract tourists to a wine region (Hall et al., 1997).

Recent research has suggested that inter-organisational networks also offer businesses valuable opportunities to enhance their marketing strategy, strengthen their competitiveness and position, and overall improve their performance leading to growth (Gnyawali and Park, 2009). This is particularly the case for SMEs, which are often challenged by a lack of marketing expertise and funds to dedicate to marketing their businesses (McCartan-Quinn and Carson, 2003). Small family owned wineries in particular are limited in terms of the promotional activities they pursue and the markets they target due to lack of financial resources and know-how.

Previous research that examined the role of collaboration and learning in Australia's wine industry found that collaboration among producers was vital for enhancing knowledge sharing and could arouse new motives and ambitions for those involved in the industry (Marsh and Shaw, 1999). Similarly, Taplin (2010) identified that networks and interaction between key players was a primary conduit for knowledge sharing among Californian 
wine producers. In turn, this cooperation assisted the region to maintain its quality reputation. In their study of the role of horizontal network relationships in the internationalisation of New Zealand SMEs, Chetty and Wilson (2003) found that wineries openly collaborated with each other for the purpose of information sharing, organisational learning, and marketing in both local and export markets. Most competition stemmed from other countries, such as Australia, rather than other New Zealand wine producers. A similar notion was raised by Beverland (2009), who indicated that collaborative relationships between competitors (in this case other wineries) enable exporting wine firms to raise the general awareness of their collective product among business buyers and consumers. Once regional awareness was established, producers could then establish more vertical relationships that would enable them to leverage their individual wine brands into the new market (Beverland, 2009). Although these studies provide evidence of the benefits of networks from a marketing perspective, further research into why, and how, wine businesses collaborate through horizontal networks is needed.

In other related literature, Mitchell and Schreiber (2007) studied the barriers to collaboration from a wine tourism perspective. Using interviews with Central Otago tourism and wine industry stakeholders, the researchers found support for the perception that most wineries do not consider themselves to be related tourism businesses. A lack of cohesion within the tourism sector, and the number of tourism marketing organisations within the region, were also identified as cause for concern. Despite their study's focus on vertical relationships and wine tourism networks, Mitchell and Schreiber (2007) found strong levels of cooperation between wine producers, which was carried out via various networks.

Similarly, Bruwer (2003; Bruwer and Alant, 2009) has performed extensive research into the nature of wine tourism in South Africa. Through an investigation of the structural dimensions of the South African wine industry, Bruwer (2003) found that wine companies were most interested in maintaining horizontal linkages with other wineries in their area, rather than strong ties with tourism enterprises and government agencies. A higher degree of networking and cooperative behaviour was therefore observed between the wineries themselves. Although South Africa has a relatively developed wine tourism sector, very few of the wine organisations situated on wine routes perceived themselves to be directly involved in the business of tourism (Bruwer, 2003). 
For the most part, the extant literature on inter-organisational relationships and collaboration within the wine industry has largely been from a wine tourism perspective. Other popular topics include the study of relationships between winemakers and wine grape suppliers (Renondo and Fierro, 2007; Somogyi et al., 2010), wine producers and their distributors (Thach and Olson, 2006), and wine producers and members of an international supply chain (Lindgreen, 2001). Some research on horizontal networks and collaboration between competing wine businesses has emerged (Taplin, 2010). However, questions still remain in relation to how competitors interact within formal networks, and what collaborative marketing outcomes these networks can realise. A key result area for the Tasmanian wine industry going forward is marketing and promotion. Networks have a key role to play in assisting to build Tasmanian wine brand recognition, grow sales and value of Tasmanian wine, attract investors to the state, and continue to improve the profitability of the region.

\section{Research context}

Despite its small population and isolated location, Tasmania has a viticultural heritage stretching back to the $1820 \mathrm{~s}$. Commercial production of wine commenced in the 1950s. Today, Tasmania has approximately 160 licensed wine producers who grow grapes from approximately 230 vineyards, covering 1,800 hectares of land (Wine Tasmania, 2015). Most Tasmanian producers sell their wine through cellar door and restaurant sales. Less than one third actively market their wines to mainland Australia, and an even smaller number export internationally. Although the whole state is still legally classified as one wine region for geographical indication (GI) purposes, there are arguably four sub-regions (see Figure 1; adapted from Wine Tasmania, 2010).

\section{INSERT FIGURE 1 HERE}

Production-wise, Tasmania contributes less than 0.5 per cent to Australia's national wine grape production [1]. However, the value of Tasmanian grapes is at least four times the national average, and bottled wine accounts for 6 per cent of Australia's overall premium wine sales. Tasmania is considered a high value and profitable region, with the majority of wine retailing for over AU\$30 per bottle (Winemakers Federation of Australia, 2013) [2]. Despite strong growth and vineyard expansion in recent years, Tasmania is still classified 
as a boutique wine region and is very 'young' compared with that of the larger regions in South Australia, Western Australia and New South Wales (Winetitles, 2010). Demand for, and consumer awareness of, Tasmanian wine is increasing, particularly for the state's most celebrated cool-climate varieties (i.e., pinot noir, chardonnay and sparkling). While the majority of mainland Australia producers have faced major oversupply issues and a decline in return per litre in export markets since 2007, Tasmanian wine has held a return of about 2.5 times the Australian average.

Formal networks between producers at a state-wide and sub-regional level represent the most prominent form of inter-organisational collaboration in the industry. Two of the networks, Wine Industry Tasmania (WIT, the state-wide 'peak' body or official association) and the Tamar Valley Wine Route (TVWR, sub-regional association), are classified as formal networks, because they have a clear hierarchical structure, agreed marketing objectives, a strategic plan, and a strict code of conduct that governs the actions of network members. The third network, WineSouth (sub-regional), is more of a semiformal network, because it does not use formal procedures to govern the behaviour of its members, it does not appear to follow an agreed strategic or marketing plan, and its members do not meet regularly.

\section{Research method}

A key aim of this research was to explore horizontal wine networks in a specific context and from multiple 'insider' perspectives (Guba and Lincoln, 1994). For this reason a qualitative approach was adopted. During stage one of the data collection, semi-structured interviews were conducted with four industry informants. In-depth secondary research relating to the Tasmanian wine industry was also carried out, and a number of Tasmanian wine events and roadshows were attended, during which unstructured participant observation was performed.

In stage two, primary data were collected via face-to-face interviews with 33 licensed Tasmanian wine producing firms that were representative of the Tasmanian wine industry in terms of size, ownership and years established. One employee from each firm was interviewed. In almost all cases, this was the owner. In the remaining cases, the interviewee was in a position of seniority, such as a Chief Executive Officer or Marketing Manager. In line with ACIL Consultants' (2003) report on the Australian wine industry, 
the size of each firm was determined according to the volume of grape they crushed (yield), rather than their number of full time equivalent employees.

Of the 33 producers interviewed, 11 were boutique-sized wine businesses (i.e., annual yield was less than 20 tonnes), 17 were classified as small businesses (i.e., annual yield was between 20 and 250 tonnes), four medium (i.e., annual yield was between 250 and 1000 tonnes), and one large (i.e., annual yield exceeded 1000 tonnes). Two wine firms that were not members of any formal industry networks at the time of data collection were also interviewed, as it was important to consider possible divergent and opposing views.

In all interviews a semi-structured interview protocol was used, which served as a 'checklist' of areas to be covered (O'Donnell and Cummins, 1999). In keeping with the study's interpretivist approach, the interviewee's own perspectives and experiences helped to determine the order and flow of questions. The average duration of the interviews was just over one hour. All interviews were recorded and the subsequent transcripts and field notes were used as the basis for data analysis. The identities of interviewees are not revealed here; rather, they are referred to by a number.

Analysis of the qualitative data was an ongoing and inductive process which entailed 'immersion' in transcripts and coding categories. A process of data reduction, data display, and conclusion drawing and verification was adopted (Miles and Huberman, 1994). First level coding was used to reduce large chunks of data into general categories of information based around the research aims, existing literature and recurrent themes. The data were then analysed further to identify patterns and relationships across the code categories. Displaying data in the form of 'tree' and 'child' nodes enabled preliminary conclusions to be drawn. These preliminary conclusions were then compared with relevant literature as part of the data verification stage. Computer aided qualitative data analysis software (QSR NVivo Version 8) assisted the research team to carry out analyses in an efficient and rigorous manner.

\section{Findings and discussion}

Analysis of the interview data revealed that wine producers enter into and benefit from horizontal networks for many reasons (as highlighted below). Although many wine 
producers tended to join horizontal networks seeking commercial and social outcomes, over time their approach to networking may evolve to be more strategic.

\section{Commercial motivations}

The need for efficiency and the desire to achieve economies-of-scale were obvious motivations for Tasmanian producers to join horizontal networks and collaborate for marketing purposes. In the region's current stage of development, horizontal networks provide opportunities for producers to improve profits, save money and resources, and generate marketing impact that is otherwise unattainable. In addition, new entrants to the industry relied on formal horizontal networks to learn about opportunities for marketing their wine product and participating in technical development workshops. This is consistent with previous research, which found tourism businesses enter into collaborative relationships to gain a better understanding of the marketplace and broaden their capabilities and knowledge base (Wang and Fesenmaier, 2007).

\section{Leveraging event marketing}

The notion that many wine producers feel isolated in their small business also motivated them to engage in formal horizontal networks. For these producers in particular, networks offered access to more experienced winemakers and the ability to participate in marketing activities only possible through networks such as events, trade shows, and national newspaper advertising. Since 2008 Tasmania's state-wide network has organised interstate roadshows, which involve members paying an additional cost (on top of their network membership fee) to showcase their wine at tasting events in Brisbane, Melbourne and Sydney. The sub-regional networks also organise similar, yet smaller scale events in both Tasmania's capital city Hobart, and largest northern city Launceston. The aim of these events are to allow both members of the public and trade professionals to taste Tasmanian wine and learn more about the producers in that sub region. Often the events feature 'masterclass' style presentations, and are complemented with Tasmanian food offerings to enhance the experience.

From a producer's perspective these events allow them to increase brand recognition, meet distributors and sommeliers, and promote a united front. Two of these events, the White Wine Weekend and Red Wine Weekend, even involve network members personally selling each other's products, as stalls at the event are organised by grape variety rather 
than individual wine brand.

For smaller producers in particular, public network events are often the only avenue for them to promote their wine, especially if they do not have a cellar door. From a collaborative perspective, events help to market the region and build awareness of the collective Tasmanian wine brand. This has flow on benefits to sales, recognition, and demand for individual wine brands. Comments by Producer 1 illustrate this finding:

The challenge for us is getting known basically, which is why we rely so heavily on collaborative things. If you are a small vineyard, and you don't have a cellar door and you don't have any other window to the public, you need to tag on with other vineyards, hopefully from the same area, in order to get [noticed].

\section{Enhancing the identity and awareness of the Tasmanian wine brand}

A number of interviewees supported the idea that collaborative marketing of the Tasmanian wine brand through horizontal networks was vital to establishing a regional reputation that could stand out in an increasingly competitive environment. This is consistent with current literature, which suggests small firms can access resources and new markets through collaborating with other firms in a network environment (Street and Cameron, 2007). Furthermore, research from a wine tourism perspective has found that networks, industry associations, and marketing alliances are ideal for smaller producers looking to expand their marketing scope and take advantage of branding and cost efficiencies (Hall, 2003; Telfer, 2001 ). Producer 14, a mid-sized wine business located in Southern Tasmania, commented:

I think Tasmania is so small that we need to promote Tasmanian wine first...of course we have to promote our own vineyards and our own style and brand, but I think there is a lot to be said for working together as a group... The production here is so small that until the market is pretty big, there is no sense battling your neighbour when they are trying to promote the same thing.

Many others made similar comments, arguing that horizontal networks helped the industry to promote a united front, and create awareness of the collective Tasmanian wine brand on a national and international scale. Collaborative marketing by horizontal networks also assisted in raising awareness of Tasmania as a wine tourism destination. Most Tasmanian wine producers rely heavily on cellar door and restaurant sales. Consequently, many refer wine tourists to neighbouring cellar doors. In one network, this practice was even stipulated in the network's own 'code of conduct'. There were also cases of network 
members securing a collaborative agreement with a distributor or restaurant, and more generally introducing each other to key contacts.

\section{Lobbying and a collective voice}

Some interviewees also acknowledged the lobbying role played by horizontal networks, particularly by the state-wide wine industry association. The degree to which this motivated producers to join networks varied, and was largely dependent on the size of the wine business and the attitudes of its owner/managers. What was clear was that individual producers, or even individual sub-regions, lack the 'pulling power' to lobby government for access to funds or changes to legislation. Change is more likely when government perceives the industry to be cohesive. As one producer remarked 'as soon as an industry shows signs of fragmenting, the government tends to step back' (Producer 32).

Although interviewees mostly expressed positive experiences of horizontal networking, not all producers felt networks were 'actually effective at increasing sales to the people who spent the time and money to participate' (Producer 18). They agreed that collaboration and networking raises the profile of the industry, but it was the responsibility of individuals to convert this exposure into a commercial outcome. This negative reaction to too much 'networking' was particularly evident in the sub-regional networks that were relatively informal and insular, where some members regarded the network as 'timewasting' and mostly a 'feel good thing'. However, negative perceptions of collaboration and networking were also related to the development stage and maturity of the network. The state's two more formal, and long-standing networks had 'codes of conduct', which among other things governed how member meetings were facilitated, and stipulated standards for the service provided to cellar door visitors and tourists. Both of these networks also had marketing committees, a strategic plan and conducted regular planning days. These initiatives provided clear direction regarding the type of activities the network would pursue and how these activities would enable the network to achieve its objectives. In turn members of these networks could more easily identify the benefits of collaborative marketing and make decisions regarding which activities they wanted to be involved in. ,

\section{Social motivations}

Despite the perceived commercial benefits obtained from horizontal networking, there was also a strong inclination for producers to join horizontal networks for social reasons. The 
wine industry has traditionally been characterised by a culture of socialising and sharing knowledge, particularly among vignerons who enter the industry for lifestyle reasons. In this study, the level of camaraderie was very high. For some, the chance to meet and socialise with producers in their area enabled them to escape the everyday 'perils' of managing a small wine business.

Social interaction was also associated with access to intangible resources such as knowledge and information. As Producer 32 explained:

[Small growers] can pick up the phone and ring me and any number of others, but it is not as easy as casually seeing somebody at a meeting or field day...if you don't rub shoulders with people you don't come across those opportunities and you get stuck. No man is an island. Horizontal networks could also provide producers with a welcome and accessible environment for basic interaction, which they lacked within their own businesses or vertical networks and distribution channels. In particular, this type of social interaction was a powerful motivator for the smaller and less experienced producers to become part of networks. At public tasting events, for example, smaller wine producers had the opportunity to observe 'how things were done' by the more experienced and sophisticated producers. This even extended to taking note of how these producers promoted their wine brand with banners, collateral and merchandise:

I know that some of the really smaller vineyards, or the quieter members of the group, go to nearly every meeting and do things because they just want that interchange. They want to see what others are doing and find out how they can improve. (Producer 11)

For other producers, who did not perceive there to be any real commercial benefit to horizontal networks, network meetings and events were still a valuable opportunity for socialising and generally 'catching up'. To some extent this feeling was expressed as loyalty to the current producers, and obligation to maintain the strong sense of camaraderie that was established by the industry's pioneers, and the original vineyards association.

Strong feelings of camaraderie and unity motivated many other producers to join horizontal networks and participate in collaborative marketing activity. For example:

Generally I think everyone in the Tasmanian industry has the feeling that you are all in it together... it is not so much a "them thing" it is a "we thing". (Producer 5) 
This desire to support the industry was evident not only through the comments producers made, but also at industry events and meetings. Some producers admitted that although there was little financial payback from participating in certain collaborative marketing events, they continued to support the network because of the social outcomes involved. That is why we participate in things like Tasmania Unbottled, even though we did it last year and had virtually no wine...I still think it is important to be there and to support your industry and do what you can. (Producer 5)

I think it shows the energy of the people and it improves what everyone else is offering because they start offering themselves as part of something. Rather than doing something off one side, they start doing it together. (Producer 22)

There were, however, some respondents who were more critical and dubious of 'all this altogetherness' (Producer 12) particularly in relation to events and festivals. These producers tended to be larger scale, and were targeting markets overseas rather than investing in wine tourism.

In the case of wine, social relationships and calling on others for advice are considered a natural and inherent aspect of the industry. Instead of commencing with a business relationship that leads to a social relationship, producers often start out as friends or neighbours, and as they develop trust, they seize opportunities in the way of commercial efficiencies and economic exchange. This trend was evident not only within relationships between neighbouring firms but also at a sub-regional network level. For example, Tasmania's oldest sub-regional network has evolved from a small, informal group of producers into a sophisticated marketing enterprise and recognisable brand. Almost all of the members interviewed described this network favourably. One member, who had moved to Tasmania from mainland Australia, commented that:

I have never seen a group of people work so well together to get so much done... I would challenge anyone to find a more organised wine route anywhere. I just think it is amazing' (Producer 19).

The strong social relationships and network ties embedded within this particular network enabled producers to overcome many of the common issues associated with intercompetitor collaboration such as perceived risk, lack of trust, poor commitment and difficulty in reaching consensus (Morris et al., 2007). The array of social motivations revealed in this study are also consistent with prior research by Wargenau and Che (2006), 
who found that strong relationships between producers along the Southwest Michigan Wine Trail was significant in raising the profile of the region as a wine tourism destination.

\section{Strategic motivations}

As already suggested in the comments above, the size of the wine business, and the owner/manager's background, influenced their motivations for horizontal networking. In this study, a common theme among 'next-generation' winemakers, or those who managed a larger-sized wine business, was their desire and willingness to assume leadership positions within networks for strategic reasons. A small portion of Tasmanian wine producers have experienced fairly rapid growth, hence they have good financial and marketing resources. These larger-scale wine businesses are also key players in wine tourism, and/or have a diverse range of assets and capabilities. As a result, their internal expertise and resources were strong, and this was found to reduce the incentive to rely on horizontal networks for market exposure and knowledge. Producer 2, for example, felt their involvement in networks was not so much of a commercial necessity, but rather part of their overall business strategy:

We are pretty much involved in a lot of those sorts of bodies, and we like to have an involvement in the operations, whether it is at a committee level or whatever else, because at least that way you know what is going on. We have also got the resources to be able to put people into those sorts of committees.

These producers recognised that their role in the networks was different to the boutiquesized vineyards. The human resources they had within their business afforded them the opportunity to assume leadership roles. This enabled them to voice their opinions regarding the direction of the industry and in turn increase their influence over networkbased decisions. For example, the following comments from a mid-sized family-owned business add support to this motivation:

It is great that [individual name] is on the marketing committee because at least we get some say in the wine route brochure and in other marketing activities...I am also on the technical committee for WIT...so it is nice to be part of the information and trying to decide what is worth talking about and what isn't. (Producer 31)

\section{Marketing coordination and integration}

Being active in both the state-wide and sub-regional network also allowed producers to maximise their gain from collaborative marketing because they could coordinate their marketing strategies with those of the networks, and increase their presence and position 
in the industry. Many of the state's young winemakers had also adopted a more strategic and targeted approach to their networking behaviour. For these producers, their future and survival in the industry was somewhat dependent on who they chose to work with and where they could exert their leadership potential.

\section{Respect and responsibility}

From a different perspective, Tasmania's larger scale producers had been 'more targeted' in their decisions to join horizontal networks and engage in collaborative marketing, because they felt a sense of responsibility and loyalty:

Number 1 is that there is our own desire to be presenting our product and presenting ourselves to the market. But there is also almost a requirement as one of the larger in the state that we should be making our contribution to marketing and promoting the state generically. I think there is a bit of a responsibility to do that, and at the end of the day it is still in our interests to do it.

(Producer 2)

For Tasmania's smaller producers, and those who were less active in the industry, horizontal networks enabled them to improve their credibility and standing within the industry. This had flow on benefits to them being respected by their peers and forming reciprocal relationships. For many smaller producers, ongoing and regular presence at network meetings, events and field days demonstrated their commitment to the network and wider Tasmanian industry. Producer 5, for example, stated:

Because we have participated in state things like Tasmania Unbottled and we are up at meetings all the time, people are starting to recognise there are some decent wineries outside of their area...it enhances your credibility if you know what is going on, apart from just what is going on in your own four walls.

This is consistent with previous studies examining the nature of networks in tourism and destination marketing. Wang and Fesenmaier (2007), for example, found that organisations often join networks and industry bodies because of a perceived social responsibility and desire to increase goodwill in the community.

In summary, wine producers join horizontal networks for a variety of reasons, some social and some more commercial and strategic. The variation relates to the diverse range of backgrounds and objectives of owner/managers operating in the wine industry, but in Tasmania's case, it is also related to the perception that the state-wide network fulfils a different role to the two sub-regional networks. Because of their quantifiable and more tangible nature, commercial, cost-based benefits tended to be the most widely 
acknowledged by the interviewees, particularly those representing very small or newly established Tasmanian wine businesses. However, many producers came to realise that the less tangible and social aspects of horizontal networking offer strategic and relational value to their business over the long-term.

\section{Conclusions}

This study aimed to explore why small producers in a boutique wine region join horizontal networks, and the benefits of doing so. Insights have been presented into how such networks can be of benefit at an individual and industry level. Comparisons were made between state-wide networks and those located at a sub-regional level. Thus, our study supports previous research which has found networks formed between geographically proximate firms tend to be more collaborative (Inkpen and Tsang, 2005). In addition, this study concludes that networks which are governed by actual members and involve frequent social activity provide a stronger foundation for mutual benefits and collaborative arrangements.

For most producers, the initial motivation for entering a horizontal network was based on commercial reasons, such as economies of scale, resource efficiency, risk sharing, and access to equipment. However, as the owner/manager became more involved in a network and the industry, these benefits evolved to be more strategic and intangible. For example, this research found that business networks provide producers with ease of access to new resources, specific industry information, and technological know-how.

Most interviewees also had multiple reasons for joining one or more networks. Such motivations changed over time, depending on the owner/manager's expertise and experience, and the types of marketing activities the network pursued. Some differences were also found in relation to producers' motivations for joining the official state-wide association, WIT, versus their reasons for joining a sub-regional network. In particular, there was a stronger desire from a social standpoint for being involved with a sub-regional network. This is partly because most interviewees interacted more frequently with producers in their sub-region, and were more open to sharing ideas and experiences in this informal way. Thus, relationships on a personal level developed easily. 
It should be noted that not all Tasmanian producers are members of WIT; membership is not compulsory and is considered by some to be too costly. Another reason producers avoided this network was because they would rather invest their time and resources into developing the reputation and awareness of their sub-region, rather than the state as a whole. The implications of this are that the sub-regional networks may become more active in collaborative marketing activities and their presence more significant. At the same time, new problems may arise given that some of Tasmania's more remote and rural sub-regions (for example, the North West and the East Coast) lack the geographic concentration and critical mass necessary to establish a viable formal horizontal network. Industry fragmentation may also reduce the lobbying power and influence of the peak body, which could have detrimental effects on the support given to the industry by government.

Theoretically, the study has explicitly recognised why producers join wine networks and what the various facets behind these motivations are, as shown by our tripartite categorisation. It would be useful to extend this research to other wine regions, with the aim of understanding why formal horizontal networks have been formed and how they currently operate. With a view to further developing theory around horizontal network behaviour, research might focus on establishing quantitatively the extent to which the motivational phenomena identified in Tasmania are prevalent in wine regions elsewhere. Greater understanding of the different aspects of collaboration at play in different wine industry settings will enable wine businesses to maximise the benefits of working together, and governments and industry bodies to allocate resources towards encouraging more collaborative and effective efforts. Another stream of future research relates to the notion of inter-regional rivalry. By studying the implications of inter-network competition within a single wine region, questions such as at what point, and under what circumstances, wine producer behaviour within horizontal networks becomes more competitive should be addressed.

This paper has shown how collaborative marketing and horizontal networks have, through time, become a commonplace and beneficial activity for premium wine producers. This networking has strengthened the bonds between wine producers at both a sub-regional and state-wide level, and arguably more so for the former. Whether for reasons of proximity, 
isolation, or both, the industry environment in which producers operate does impact on the establishment and longevity of the horizontal network.

\section{Notes}

1. Between 2010 and 2012, annual wine grape production in Tasmania averaged around 7,500 tonnes. In 2013, it increased to 11,392 tonnes, but fell to 6,624 tonnes in 2014. The largest yielding region is the Tamar Valley, representing around $40 \%$ of wine production (Wine Tasmania, 2013; 2014).

2. AU $\$ 1=\mathrm{US} \$ 0.77$ as at 13 February 2015.

\section{References}

ACIL Consultants (2003), Pathways to Profitability for Small and Medium Wineries. A Report Commissioned by the Department of Agriculture, Fisheries and Forestry Australia, ACIL Consulting Pty Ltd, Melbourne.

Anderson, J. C., Håkansson, H. and Johanson, J. (1994), "Dyadic business relationships within a business network context", Journal of Marketing, Vol. 58 No. 4, pp. 1-15.

Anderson, K. (2001), "Prospects ahead for the wine industry", CIES Wine Policy Brief Vol. 7, University of Adelaide, Adelaide.

Aylward, D. (2006), "Profiling successful SME exporters within the Australian wine industry", International Journal of Technologv. Policv and Management, Vol. 6 No. 1, pp. $49-65$.

Bengtsson, M. and Kock, S. (2000), “'Coopetition” in business networks: to cooperate and compete simultaneously", Industrial Marketing Management, Vol. 29 No. 5, pp. 41126.

Beverland, M. (2009), "Boundary conditions to business relationships in China: the case of selling wine in China", Journal of Business \& Industrial Marketing, Vol. 24 No. 1, pp. 27-34. 
Brown, B. and Butler, J.E. (1995), "Competitors as allies: a study of entrepreneurial networks in the US wine industry", Journal of Small Business Management, Vol. 33 No. 3, pp. 57-65.

Bruwer, J. (2003), "South African wine routes: some perspectives on the wine tourism industry's structural dimensions and wine tourism product", Tourism Management, Vol. 24 No. 4, pp. 423-35.

Bruwer, J. and Alant, K. (2009), "The hedonic nature of wine tourism consumption: an experiential view", International Journal of Wine Business Research, Vol. 21 No. 3, pp. 235-257.

Cafaggi, F. and Iamiceli, P. (2010), "Inter-firm networks in the European wine industry", working paper [2010/19], Department of Law, European University Institute, Florence, 2010.

Carlsen, J., Dowling, R. and Cowan, E. (1998), "Wine tourism marketing issues in Australia", International Journal of Wine Marketing, Vol. 10 No. 3, pp. 23-32.

Chetty, S.K. and Wilson, H.I.M. (2003), "Collaborating with competitors to acquire resources”, International Business Review, Vol. 12 No. 1, pp. 61-81.

Cova, B., Prévot, F. and Spencer, R. (2010), "Navigating between dyads and networks", Industrial Marketing Management, Vol. 39 No. 1, pp. 879-886.

Easton, G. and Araujo, L. (1992), "Non-economic exchange in industrial networks", in Axelsson, B. and Easton, G. (Eds.), Industrial Networks: A New View of Reality, Routledge, London, pp. 62-84.

Fyall, A. and Garrod, B. (2005), Tourism Marketing: A Collaborative Approach, Channel View Publications, Tonawanda, NY.

Gnyawali, D.R. and Madhavan, R. (2001), "Cooperative networks and competitive dynamics: a structural embeddedness perspective", Academv of Management Review, Vol. 26 No. 3, pp. 431-45.

Gnyawali, D.R. and Park, B.J.R. (2009), "Co-opetition and technological innovation in small and medium-sized enterprises: a multilevel conceptual model”, Journal of Small Business Management, Vol. 47 No. 3, pp. 308-30. 
Granovetter, M.S. (1973), "The strength of weak ties", American Journal of Sociology, Vol. 78 No. 6, pp. 1360-80.

Guba, E.G. and Lincoln, Y.S. (1994), "Competing paradigms in qualitative research", in Denzin, N.K. and Lincoln, Y.S. (Eds.), Handbook of Qualitative Research, Sage, Thousand Oaks, CA, pp. 105-17.

Håkansson, H. (Ed.) (1982), International Marketing and Purchasing of Industrial Goods: An Interaction Approach, John Wiley, Chichester.

Hall, C.M. (2003), "Wine and food tourism networks: a comparative study", in Pavlovich, K. and Akoorie, M. (Eds.), Strategic Alliances and Collaborative Partnerships: A Case Book, Dunmore Press, Palmerston North, pp. 258-68.

Hall, C. M., Cambourne, B., Macionis, N. and Johnson, G. (1997), "Wine tourism and network development in Australia and New Zealand: review, establishment and prospects", International Journal of Wine Marketing, Vol. 9 No. 2/3, pp. 5-31.

Harbison, J.R. and Pekar, P.P. (1998), Smart Alliances: A Practical Guide to Repeatable Success, Jossey-Bass, San Francisco, CA.

Henry, P. (2008), “The case for a collaborative approach", Australian and New Zealand Wine Industry Journal, Vol. 23 No. 3, pp. 42-3.

Inkpen, A.C. and Tsang, E.W.K. (2005), "Social capital, networks, and knowledge transfer". Academv of Management Review, Vol. 30 No. 1, pp. 146-65.

Jordan, R., Zidda, P. and Lockshin, L. (2007), “Behind the Australian wine industry's success: does environment matter?", International Journal of Wine Business Research, Vol. 19 No. 1, pp. 14-32.

Lindgreen, A. (2001), "An exploration of contemporary marketing practices in the New Zealand wine sector”, International Journal of Wine Marketing, Vol. 13 No 1, pp. 5-22.

McCartan-Quinn, D. and Carson, D. (2003), "Issues which impact upon marketing in the small firm", Small Business Economics, Vol. 21 No. 2, pp. 201-13.

Marsh, I. and Shaw, B. (1999), "Collaboration and learning in Australia's wine industry", Australian and New Zealand Wine Industry Journal, Vol. 14 No. 5, pp. 105-19. 
Miles, M.B. and Huberman, A.M. (1994), Qualitative Data Analysis: An Expanded Sourcebook, 2nd ed., Sage, Thousand Oaks, CA.

Mitchell, R.D. and Schreiber, C. (2007), "Wine tourism networks and clusters: operation and barriers in New Zealand", in Michael, E. (Ed.), Micro-Clusters and Networks: The Growth of Tourism, Elsevier, London, pp. 79-106.

Möller, K. and Rajala, A. (2007), "Rise of strategic nets: new modes of value creation", Industrial Marketing Management, Vol. 36 No. 7, pp. 895-908.

Morris, M.H., Koçak, A. and Özer, A. (2007), “Coopetition as a small business strategy: implications for performance”, Journal of Small Business Strategy, Vol. 18 No. 1, pp. 3555.

Mueller, R.A.E and Sumner, D.A. (2006), "Clusters of grapes and wine”, work-inprogress paper presented at the Third International Wine Business and Marketing Research Conference, 6-8 July, Montpellier, France, available at: http://academyofwinebusiness.com/wp-content/uploads/2010/05/Muller-R.pdf (accessed 6 February 2015).

O'Donnell, A. and Cummins, D. (1999), "The use of qualitative methods to research networking in SMEs", Oualitative Market Research, Vol. 2 No. 2, pp. 82-91.

Porter, M.E. and Fuller, M.B. (1986), "Coalitions and global strategy”, in Porter, M.E. (Ed.), Competition in Global Industries, Harvard Business School Press, Boston, MA, 315-43.

Randall, C. and Mitchell, R. (2008), "Wine tourism marketing alliances: application of importance-performance analysis", Tourism Recreation Research, Vol. 33 No. 3, pp. 289302.

Redondo, Y.P. and Fierro, J.J.C. (2007), “Assessment and reassessment of supply relationships: a case study in the Spanish wine industry", International Journal of Entrepreneurial Behaviour \& Research, Vol. 13 No. 2, pp. 82-106.

Somogyi, S. (2013), "Grape grower and winery relationships: a segmentation approach", International Journal of Wine Business Research, Vol. 25 No. 4, 252-66. 
Somogyi, S., Gyau, A., Li, E. and Bruwer, J. (2010), "Enhancing long-term grape grower/winery relationships in the Australian wine industry", International Journal of Wine Business Research, Vol. 22 No. 1, pp. 27-41.

Street, C.T. and Cameron, A. (2007), "External relationships and the small business: a review of small business alliance and network research", Journal of Small Business Management, Vol. 45 No. 2, pp. 239-66.

Taplin, I.M. (2010), "From co-operation to competition: market transformation among elite Napa Valley wine producers", International Journal of Wine Business Research, Vol. 22 No. 1, pp. 6-26.

Telfer, D.J. (2001), "Strategic alliances along the Niagara wine route", Tourism Management, Vol. 22 No. 1, pp. 21-30.

Thach, E.C. and Olsen, J. (2006), "Building strategic partnerships in wine marketing: implications for wine distribution", Journal of Food Products Marketing, Vol. 12 No. 3, pp. 71-86.

Wang, Y. and Fesenmaier, D.R. (2007), "Collaborative destination marketing: a case study of Elkhart county, Indiana”, Tourism Management, Vol. 28 No. 3, pp. 863-75.

Wargenau, A. and Che, D. (2006), "Wine tourism development and marketing strategies in Southwest Michigan", International Journal of Wine Marketing, Vol. 18 No. 1, pp. 4560.

Winemakers Federation of Australia (2013), "Wine industry report: Expert report on the profitability and dynamics of the Australian wine industry", report prepared for Winemakers Federation of Australia by Centaurus Partners, August, available at: http://www.wfa.org.au/assets/noticeboard/Expert-Review-Report.pdf (accessed 11 April 2014).

Winetitles (2010), The Australian and New Zealand Wine Industry Directory, 28th ed., Winetitles, Broadview, SA.

Wine Tasmania (2010), "The wine route", available at:

http://www.winetasmania.com.au/wine-route (accessed 22 March 2010). 
Wine Tasmania (2013), "2013 Tasmanian Vintage Report”, available at http://winetasmania.com.au/resources/downloads/130981_Wine_Tasmania_Vintage_Repo rt_2013.pdf (accessed 19 May 2014).

Wine Tasmania (2014), “2014 Tasmanian Vintage Report”, available at http://winetasmania.com.au/resources/downloads/Wine_Tasmania_Vintage_Report_2014 FINAL.pdf (accessed 13 February 2014).

Wine Tasmania (2015), “About our wine”, available at: http://winetasmania.com.au/about_our_wine (accessed 22 April 2015).

\section{Author biographies}

Gemma K. Lewis - Dr Lewis is a Lecturer in Management with the Tasmanian School of Business and Economics at the University of Tasmania. Her research interests include small business, inter-organisational collaboration, entrepreneurial marketing and value chain innovation and adaptation in the agribusiness sector.

John Byrom - Dr Byrom is Lecturer in Marketing at Manchester Business School and Visiting Senior Lecturer at the University of Tasmania. He is also Academic International Coordinator within MBS, where he oversees collaborative arrangements with international partners. His research interests include retail marketing and place management.

Martin Grimmer - Dr Grimmer is an Associate Professor in the Tasmanian School of Business and Economics, at the University of Tasmania, and is currently the Deputy Dean and Head of School. His research interests include pro-environmental consumer behaviour, the effect of green marketing communications on purchase behaviour, and small business entrepreneurship. 


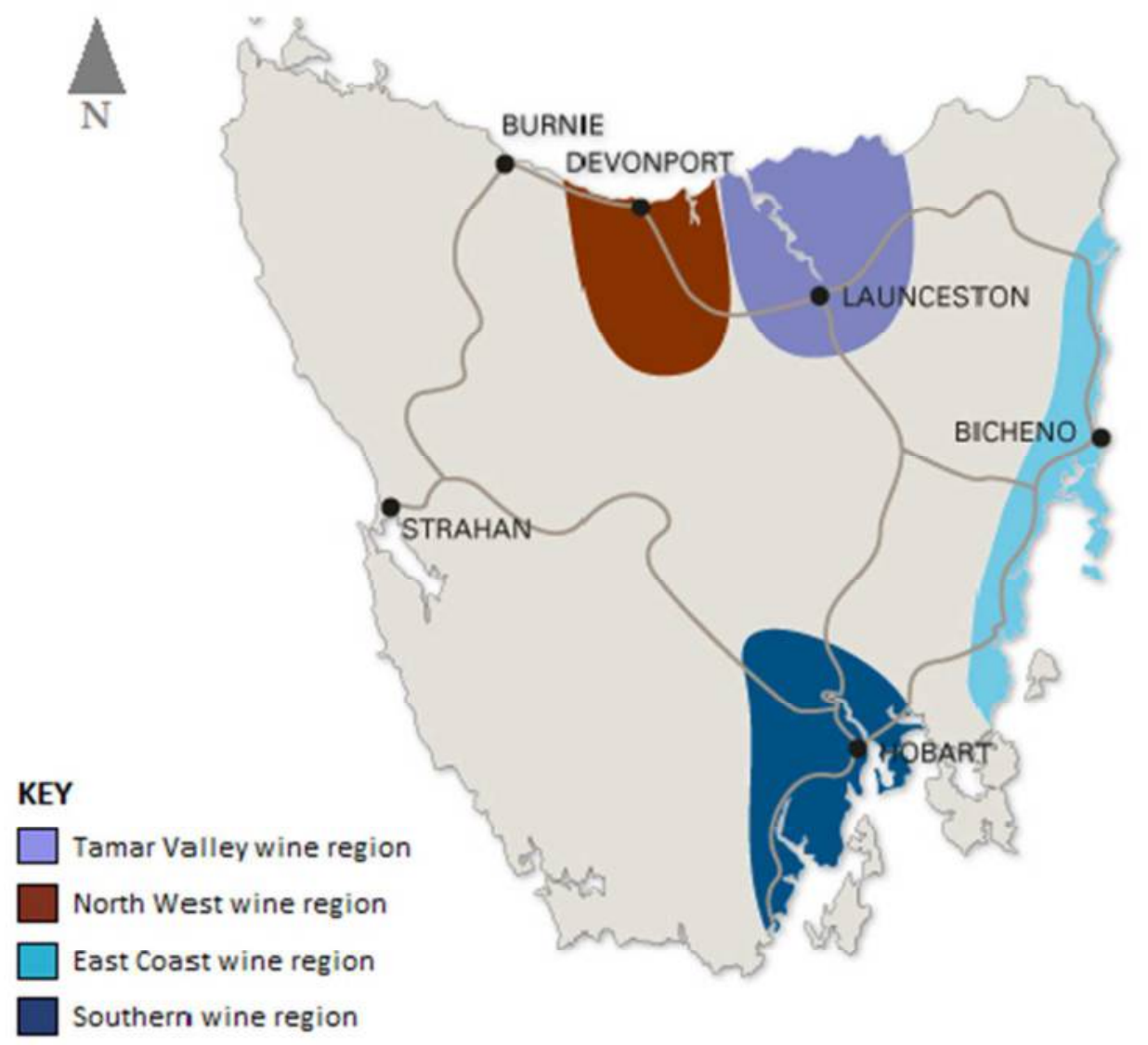

(c) Emerald Group Publishing Limited

This is a pre-print of a paper and is subject to change before publication. This pre-print is made available with the understanding that it will not be reproduced or stored in a retrieval system without the permission of Emerald Group Publishing Limited. 